\title{
CINÉTICA DE EXPRESIÓN DE INMUNOGLOBULINA A EN EL EPITELIO INTESTINAL DE CRÍAS DE ALPACA (Vicugna pacos)
}

\author{
Kinetics of ExPRESSION OF IMMUNOGLOBULin A in INTESTINAL EPITHELIUM OF \\ NeWborn Alpaca (Vicugna pacos)
}

\author{
Juan Dionisio C. ${ }^{1}$, Alberto Manchego S., ${ }^{1,4}$ Kim Lam Chiok C. ${ }^{1}$, \\ Nieves Sandoval C. ${ }^{2}$, Juan More B. ${ }^{1}$, Danilo Pezo C. ${ }^{3}$, Hermelinda Rivera G. ${ }^{1}$
}

\section{Resumen}

El presente estudio tuvo como objetivo determinar y comparar los niveles de expresión relativa de ARN mensajero (ARNm) de IgA en el epitelio intestinal de las crías de alpacas en aparente buen estado de salud $(n=35)$ o enfermas con enteropatía $(n=35)$. En cada grupo se incluyeron cinco animales recién nacidos antes del consumo de calostro y cinco por cada semana de edad hasta la sexta semana. Se tomaron $2 \mathrm{~cm}$ de yeyuno por animal y se almacenaron en congelación a $-196^{\circ} \mathrm{C}$. Se realizó la extracción de ARN total con Trizol® y luego se sintetizó el ADN complementario (ADNc). Posteriormente se realizó el PCR y la RT-PCR Tiempo Real empleando oligonucleótidos diseñados para la detección del exón 1 de la región Fc IgA de alpaca. Se realizó la cuantificación de la expresión relativa mediante normalización con ARNm del gen GAPDH y los cálculos de la expresión relativa se realizaron utilizando el método $2^{-\triangle \Delta \mathrm{Ct}}$. Se identificó y demostró mediante la técnica de RT-PCR tiempo real que las alpacas codifican y transcriben ARNm del exón 1 de la región Fc de IgA desde el primer día de edad, mas no al nacimiento; siendo su expresión relativa detectada y producida en la mucosa intestinal de crías de alpacas a partir de un día de edad, tanto en animales sanos como enfermos. Los animales sanos presentaron una tendencia de expresión constante de ARNm de IgA hasta la cuarta semana de edad, con disminución discreta en las semanas subsiguientes, mientras que la producción de ARNm de IgA en los cuadros entéricos fue siempre superior a lo expresado por los animales sanos. Se encontraron diferencias significativas $(\mathrm{p}<0.05)$ entre grupos (sanos 38.8 y enfermos 113 veces, respectivamente, respecto del calibrador).

Palabras clave: camélidos sudamericanos, inmunidad de mucosa intestinal, inmunoglobulina A, PCR, RT-PCR tiempo real, cuantificación relativa

\footnotetext{
${ }^{1}$ Laboratorio de Microbiología y Parasitología Veterinaria, ${ }^{2}$ Laboratorio de Histología, Embriología y Patología Veterinaria, Facultad de Medicina Veterinaria, Universidad Nacional Mayor de San Marcos, Lima

${ }^{3}$ Estación Experimental del Centro de Investigación IVITA, Maranganí, Cusco

${ }^{4}$ E-mail: amanchegos@gmail.com
}

Recibido: 27 de abril de 2012

Aceptado para publicación: 10 de diciembre de 2013 
The objective of the present study was to determine and compare the levels of the relative expression of messenger RNA (mRNA) of IgA in intestinal epithelium of newborn alpaca up to 45 days old, that were in good health status $(n=35)$ and ill with enteropathy $(n=35)$. In each group, five animals were newborns before the consumption of colostrum and five for each week of age until the sixth week. Samples consisted in $2 \mathrm{~cm}$ length of jejunum, which was immediately preserved at $-196^{\circ} \mathrm{C}$. The extraction was done with Trizol®, then complementary DNA (cDNA) was synthesized. Subsequently, the conventional PCR and real time RT-PCR was conducted using oligonucleotides designed for detecting the exon 1 of the Fc IgA region of alpaca. The quantification of the relative expression was made through normalization with the GAPDH gene mRNA and the relative expression calculations were conducted using the $2^{-\triangle \triangle \mathrm{Ct}}$ method. It was identified and demonstrated through the real time RT-PCR technique that alpacas encoded and transcribed mRNA of exon 1 of the IgA Fc region from the first day of age, but not at birth. Also, the relative expression is detected and produced in intestinal epithelium of newborn alpaca from one day of age, both in healthy and ill animals. Healthy animals have a tendency of constant expression of mRNA of $\operatorname{IgA}$ until the fourth week of age, with slightly decrease in the subsequent weeks, whereas in enteric diseases IgA mRNA production is always superior than the expressed by the healthy animals, having significant differences $(\mathrm{p}<0.05)$ between the two groups (healthy 38.8 and sick 113 times respectively, with regard to the calibrator).

Key words: South American camelids, intestinal mucosal immunity, immunoglobulin A, PCR, RT-PCR, relative quantification

\section{INTRODUCCIÓN}

La población de alpacas en el Perú es de casi tres millones de cabezas distribuidas mayormente en la zona central y sur del país, siendo Puno el departamento que cuenta con el $57 \%$ de esta población. La alpaca es una de las principales fuentes de trabajo para el poblador altoandino (Bustinza, 2001). Las enfermedades infecciosas son una de las mayores limitantes para el desarrollo productivo en las comunidades campesinas, donde uno de los factores de mayor impacto económico son los problemas de morbilidad y mortalidad de crías de alpaca ocasionados principalmente por enterotoxemia, neumonías y colibacilosis (Ramírez, 2009).

En general, se activa una respuesta inmunitaria a nivel de las mucosas cuando ocurre la invasión de un agente infeccioso por vía digestiva, haciendo que las células plasmáticas intestinales ubicadas en la submucosa o en la lámina propia del tracto gastrointestinal sinteticen inmunoglobulina $\mathrm{A}$ (IgA). Esta constituye la principal inmunoglobulina a nivel de mucosas que puede limitar la invasión de agentes patógenos (Braathen et al., 2007). Este tipo de inmunidad está protagonizado por los linfocitos B y $\mathrm{T}$ efectores. Las células efectoras B son las células plasmáticas productoras de inmunoglobulinas y realizan su acción mediante la inmuno-exclusión e inmuno-eliminación de los antígenos por los anticuerpos $\operatorname{IgG} \mathrm{e}$ IgM a nivel sistémico y del tipo IgA secretora, producida localmente a nivel intestinal.

Las células plasmáticas intestinales productoras de IgA derivan de linfocitos B localizados en las placas de Peyer o en los folículos solitarios (Fagarasan y Honjo, 2003). El proceso se inicia mediante el contacto del antígeno con las células presentadoras, que lo procesan y presentan a los linfocitos de las 
placas de Peyer y de los folículos, generando la proliferación de un clon antígeno-específico que pasa a la sangre, donde se distribuye como células de memoria en forma sistémica y vuelve a la lámina propia donde se aloja de forma definitiva. Ante un nuevo contacto con el antígeno, los linfocitos $\mathrm{T}$ proliferan, desencadenándose por un lado una respuesta inmune celular, y por otro, un estímulo para que los linfocitos B se transformen en células plasmáticas productoras de IgA secretora antígeno-específica (Fagarasan et al., 2001).

Se ha postulado que la principal función de la IgA es evitar la adherencia de microorganismos (bacterias y virus) en la superficie de las células mucosas, previniendo así su entrada a los tejidos (Tizard, 2000). Existen escasos estudios en camélidos sudamericanos que miden la expresión de la IgA en mucosas, tal vez debido a que no existe un método cuantitativo para medir IgA de alpaca. Debido a esto, el objetivo del presente trabajo fue determinar la expresión del ARNm de IgA en crías de alpacas y evaluar su expresión relativa durante los primeros 45 días de edad. Esto permitirá aportar al conocimiento de respuesta inmune en esta especie y, posteriormente, poder dilucidar el momento en que el neonato comienza a producir IgA propio para la defensa contra agentes patógenos.

\section{Materiales y Métodos}

\section{Animales y Muestras}

Se trabajó con 35 crías de alpacas en aparente buen estado de salud y con otras 35 crías con signos de enteropatía (presencia de diarreas y posterior confirmación por histopatología de enteritis en muestras de yeyuno) de una comunidad de criadores de alpacas del distrito de Maranganí, Cusco, Perú, en 2010. Cinco crías, aparentemente sanas, fueron trabajadas antes del consumo de calostro y cinco crías por grupo corres- pondieron a las semanas 1, 2, 3, 4, 5 y 6 de edad. Hembras y machos estuvieron representados en todas las muestras. Los animales fueron sacrificados empleando un protocolo de $1.5 \mathrm{mg} / \mathrm{kg}$ de xilacina (Rompun $\left.{ }^{\circledR}\right)$ y $7.5 \mathrm{mg} / \mathrm{kg}$ de ketamina (Vetalar ${ }^{\circledR}$ ) vía intramuscular (Urquieta et al., 1992) seguido por una sobredosis de $50 \mathrm{mg} / \mathrm{kg}$ vía endovenosa de pentobarbital sódico (Halatal®). El estudio contó con la Autorización $\mathrm{N}^{\circ}$ 2009-001 del Comité de Ética y Bienestar Animal de la Facultad de Medicina Veterinaria de la Universidad Nacional Mayor de San Marcos.

Se obtuvieron muestras de $2 \mathrm{~cm}$ de longitud de la porción media del yeyuno, por ser una región intestinal identificable, con tejido linfoide organizado y presencia de linfocitos intraepiteliales. Las muestras fueron lavadas en suero fisiológico estéril al $0.85 \%$ para retirar el contenido intestinal. Luego se realizó un raspado profundo de la mucosa con hoja de bisturí. El raspado fue diluido en $5 \mathrm{ml}$ de tampón fosfato (PBS) y centrifugado a $500 \mathrm{~g}$ por $30 \mathrm{~min}$. El sobrenadante fue descartado y el pellet obtenido, conteniendo células de la mucosa intestinal, se conservó a $-196{ }^{\circ} \mathrm{C}$.

\section{Oligonucleótidos}

Para la detección del exón 1 de IgA se emplearon los oligonucleótidos diseñados por el programa Primer3 Output (www.primer3.com) a partir de la secuencia publicada en el Banco de Genes para la línea germinal de alpaca (AM773729.1). Asimismo, se empleó el programa BLAST del NCBI (www.ncbi.nlm.nih.gov/blast/) para encontrar las regiones conservadas de la línea germinal de alpaca realizando comparaciones y demostrando su especificidad.

También se utilizaron oligonucleótidos específicos (gliceraldehído-3-fosfato deshidrogenasa) para el gen GAPDH (Patil et al., 2004) como control endógeno (Cuadro 1). El análisis BLAST con los oligonucleótidos diseñados permitió identificar parte de un producto de 309 nucleótidos del locus IgH en la 
Cuadro 1. Secuencia de oligonucleótidos para el exón 1 de la IgA y GAPDH (gliceraldehído-3-fosfato deshidrogenasa) empleados en el estudio

\begin{tabular}{|c|c|c|c|}
\hline Gen & $\begin{array}{l}\text { Longitud } \\
\text { (pb) }\end{array}$ & Secuencia & $\begin{array}{c}\mathrm{T}^{\mathrm{o}} \mathrm{de} \\
\text { hibridación }\end{array}$ \\
\hline \multirow{2}{*}{$\operatorname{Ig} \mathrm{A}$} & \multirow{2}{*}{164} & F: 5' AACGTGTCCGTCATGGACTT 3' & $60.4{ }^{\circ} \mathrm{C}$ \\
\hline & & R: 5' GGTAGTTGGGCATGTTGATC 3' & \\
\hline \multirow{2}{*}{ GAPDH } & \multirow{2}{*}{356} & F: 5' GTGAAGGTCGGAGTGAACG 3' & $60.0^{\circ} \mathrm{C}$ \\
\hline & & R: 5' GAGATGATGACCCTCTTGGC 3' & \\
\hline
\end{tabular}

Cuadro 2. Frecuencia relativa de las temperaturas de disociación (Tm) de los productos obtenidos con los oligonucleótidos para el exón 1 de la IgA en animales sanos y enfermos

\begin{tabular}{ccc}
\hline $\begin{array}{c}\text { Temperatura }\left({ }^{\circ} \mathrm{C}\right) \text { de } \\
\text { disociación }(\mathrm{Tm})\end{array}$ & $\begin{array}{c}\text { Frecuencia relativa }(\%) \text { en } \\
\text { alpacas sanas } \\
(\mathrm{A})^{1}\end{array}$ & $\begin{array}{c}\text { Frecuencia relativa (\%) en } \\
\text { alpacas enfermas } \\
(\mathrm{B})^{2}\end{array}$ \\
\hline 85.4 & 31 & 2 \\
85.7 & 56 & 6 \\
86.0 & 11 & 66 \\
87.2 & 2 & 26 \\
\hline
\end{tabular}

${ }_{2}^{1}$ Frecuencia relativa de la Tm predominante fue de $85.7^{\circ} \mathrm{C}$

${ }^{2}$ Frecuencia relativa de la Tm predominante fue de $86.0^{\circ} \mathrm{C}$

región del gen IgHV de la secuencia de la línea germinal de alpaca que comparte una identidad de $88 \%$ con el ARNm de la IgA del cerdo doméstico.

\section{Metodología del Trabajo}

Obtención de ARN total. Se empleó el reactivo Trizol® (Invitrogen, EEUU), siguiendo las instrucciones del fabricante, para la extracción de ARN total a partir del pellet obtenido de los raspados yeyunales de todos los animales. El ARN fue tratado con 2 UI DNasa (Promega, EEUU) para eliminar la presencia de ADN contaminante proveniente de las muestras.
RT-PCR. Síntesis de ADN complementario $(A D N c)$ a partir del ARN total. De cada muestra de ARN total se realizó una transcripción reversa (RT) utilizando el kit comercial «SuperScript ${ }^{\circledR}$ III First-Strand Synthesis SuperMix for qRT-PCR» (Invitrogen, EEUU) y siguiendo las especificaciones del fabricante. Se utilizó el termociclador Thermal Cycler PTC-200 Chromo 4 (MJ Research, EEUU) programado por un solo ciclo con el siguiente protocolo: $25^{\circ} \mathrm{C}$ por $10 \mathrm{~min}, 50^{\circ} \mathrm{C}$ por $30 \mathrm{~min}$, $85^{\circ} \mathrm{C}$ por 5 min y a $4^{\circ} \mathrm{C}$ indefinidamente para enfriar la muestra. Se añadió 2 UI de RNasa $\mathrm{H}$ de $E$. coli, proporcionado por el kit, a cada pocillo y se incubó a $37^{\circ} \mathrm{C}$ por 20 min para destruir la molécula ARN del híbrido 
ARN:ADNc. El ADNc obtenido fue congelado a $-70{ }^{\circ} \mathrm{C}$ hasta su uso en la reacción de PCR Tiempo Real. El software utilizado fue el Opticon Monitor 2, v. 2.0.3.

PCR. La técnica de PCR se utilizó primero mediante el método convencional para comprobar la identidad del producto de acuerdo a su longitud en pares de bases. Seguidamente, $2 \mu \mathrm{l}$ de cada ADNc junto con los oligonucleótidos específicos para el gen de la cadena pesada de la IgA (gen alfa) fue amplificado con el kit GoTaq ${ }^{\circledR}$ Green Master Mix (Promega, EEUU), siguiendo las instrucciones del fabricante. Se colocó $23 \mu 1$ del Master Mix y se agregó $2 \mu 1$ del ADNc obtenido en el paso anterior. Se colocaron los viales en el termociclador Thermal Cycler PTC200 Chromo 4 (MJ Research, EEUU). El protocolo para el termociclador fue de $94{ }^{\circ} \mathrm{C}$ por $2 \mathrm{~min}$, luego se continuó con 40 ciclos de $94{ }^{\circ} \mathrm{C}$ por $20 \mathrm{~s}, 56^{\circ} \mathrm{C}$ por $20 \mathrm{~s} \mathrm{y} 72^{\circ} \mathrm{C}$ por $40 \mathrm{~s}$. Luego se realizó una extensión final de los productos a $72{ }^{\circ} \mathrm{C}$ por $5 \mathrm{~min}$, finalizando la reacción a $14{ }^{\circ} \mathrm{C}$.

Electroforesis de los productos del PCR de IgA. Se colocaron $25 \mu \mathrm{l}$ de los productos de la PCR, se adicionaron $5 \mu 1$ de buffer de carga a cada una de las muestras, y se colocaron en los carriles del gel. Un carril fue utilizado por el marcador de peso molecular Perfect DNA 1 kb Ladder (Novagen, EEUU). La electroforesis se realizó a $100 \mathrm{~V}$ por 1 hora y luego las bandas de ADN teñidas con bromuro de etidio fueron visualizadas en un transiluminador UV (UltraLum, EEUU).

PCR en Tiempo Real. Se utilizaron $2 \mu \mathrm{de}$ cada ADNc de los ARN obtenidos durante la síntesis (del RT) para realizar un PCR Tiempo Real, utilizando el kit «SuperScript ${ }^{\circledR}$ III Platinum ${ }^{\circledR}$ SYBR $®$ Green Two-Step qRTPCR Kit w/ROX» (Invitrogen, EEUU), empleando como fluoroforos marcadores de ADN doble hebra al agente intercalante SYBR Green y el colorante Rox, y como referencia pasiva un ADN polimerasa (Taq polimerasa). Se colocó $18 \mu 1$ del Master Mix y se transfirió $2 \mu 1$ de ADNc obtenido. Se colocaron los viales en el termociclador PTC 200 Chromo 4 programado con el siguiente protocolo: $50^{\circ} \mathrm{C}$ por $2 \mathrm{~min}, 95^{\circ} \mathrm{C}$ por $2 \mathrm{~min}$, seguido de 40 ciclos de $95^{\circ} \mathrm{C}$ por 15 s y $60^{\circ} \mathrm{C}$ por $1 \mathrm{~min}$. Los productos fueron leídos por el termociclador para PCR tiempo real generando una curva de amplificación o ciclo umbral $(\mathrm{Ct})$ y una curva de disociación $(\mathrm{Tm})$, determinando su especificidad. El software empleado fue Opticon Monitor 2, v. 2.0.3.

\section{Resultados}

Los resultados del PCR convencional usando los oligonucleótidos diseñados para el ARNm de la IgA evidenciaron la amplificación de un producto específico de aproximadamente $164 \mathrm{pb}$ a partir de ADNc obtenido. No se logró observar diferencias entre los productos obtenidos de muestras de animales sanos y enfermos o por el efecto de la edad a través de la técnica convencional (Fig. 1).

Las frecuencias de las temperaturas de disociación de los productos obtenidos en las crías sanas muestra la predominancia de un producto con $\mathrm{Tm}$ de $85.7^{\circ} \mathrm{C}$, mientras que en el grupo de crías enfermas el producto predominante posee una $\mathrm{Tm}$ de $86.0^{\circ} \mathrm{C}$ (Cuadro 2).

En la expresión del ARNm de la IgA, las temperaturas de disociación fueron cercanas entre los amplicones obtenidos (Fig. 2).

En la cuantificación relativa de ARNm de IgA, los resultados mostraron que el nivel promedio de expresión de ARNm de IgA en animales sanos fue de 38.8 veces respecto del calibrador (1 día de edad). Por el contrario, los animales enfermos con enteropatía producen 113 veces lo expresado por el calibrador, existiendo diferencia significativa $(\mathrm{p}<0.05)$ entre el grupo de animales sanos y enfermos (Fig. 3). 


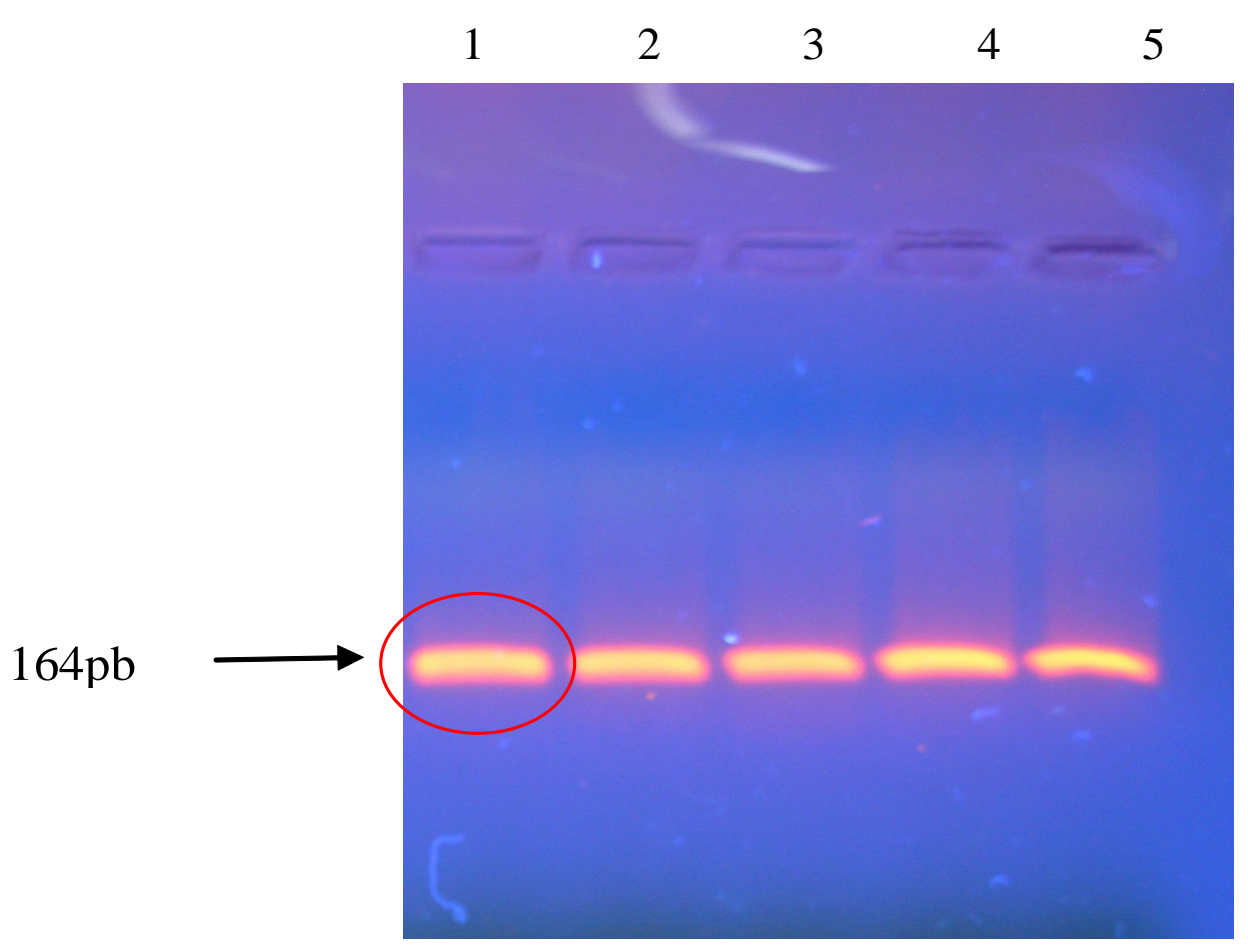

Figura 1. Electroforesis en gel de agarosa $1.5 \%$ de los productos de PCR para detección del exón 1 de la cadena pesada de IgA. 1: Alpaca sana de 5 días de edad, 2: Alpaca sana de 1 día de edad, 3: Alpaca sana de 23 días de edad, 4: Alpaca enferma de 24 días de edad, 5: Alpaca sana de 35 días de edad

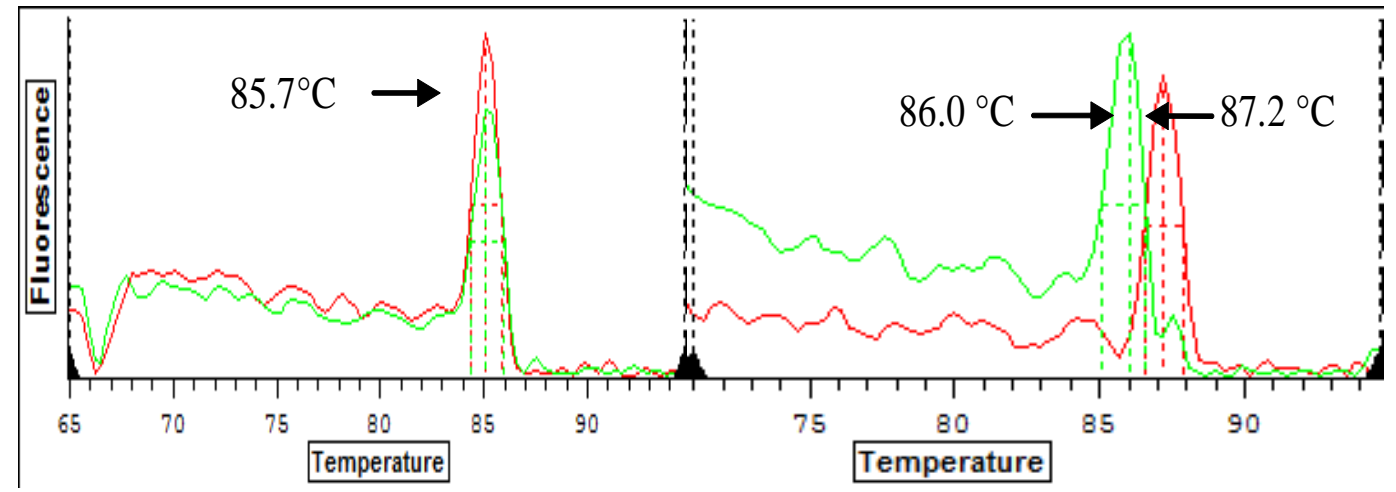

A

B

Figura 2. Análisis de Temperatura de Disociación (Tm) mediante RT-PCR Tiempo Real. A) Animales sanos, la curva verde representa un producto con Tm de $85.7^{\circ} \mathrm{C}$. B) Animales enfermos, la curva verde muestra otro producto con Tm de $86^{\circ} \mathrm{C}$, y la curva roja muestra un producto con $\mathrm{Tm}$ de $87.2^{\circ} \mathrm{C}$ 


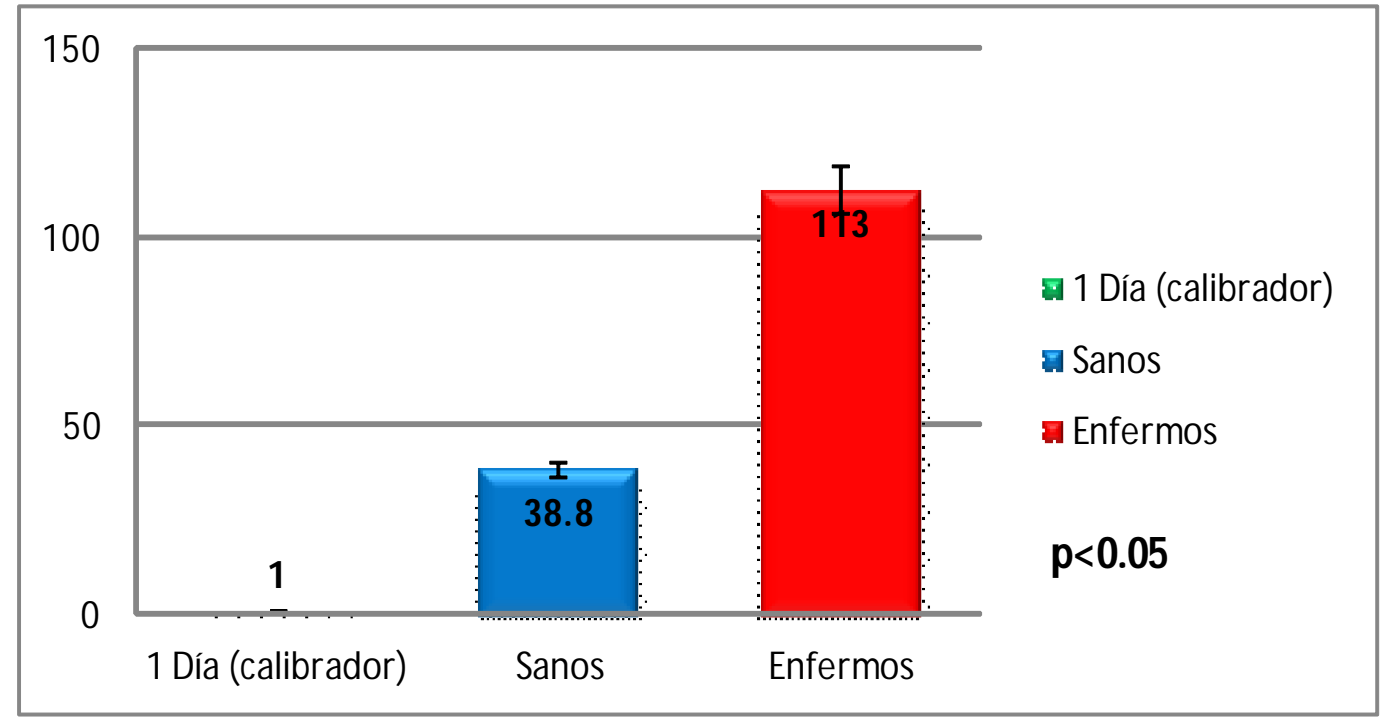

Figura 3. Variación de la expresión relativa de ARNm de $\operatorname{IgA}$ en mucosa intestinal de crías de alpacas sanas y enfermas con respecto al calibrador. Según estado sanitario en relación a la expresión al día de edad según el método $2^{-\Delta \Delta \mathrm{Ct}}$ en animales de 0 a 45 días de edad

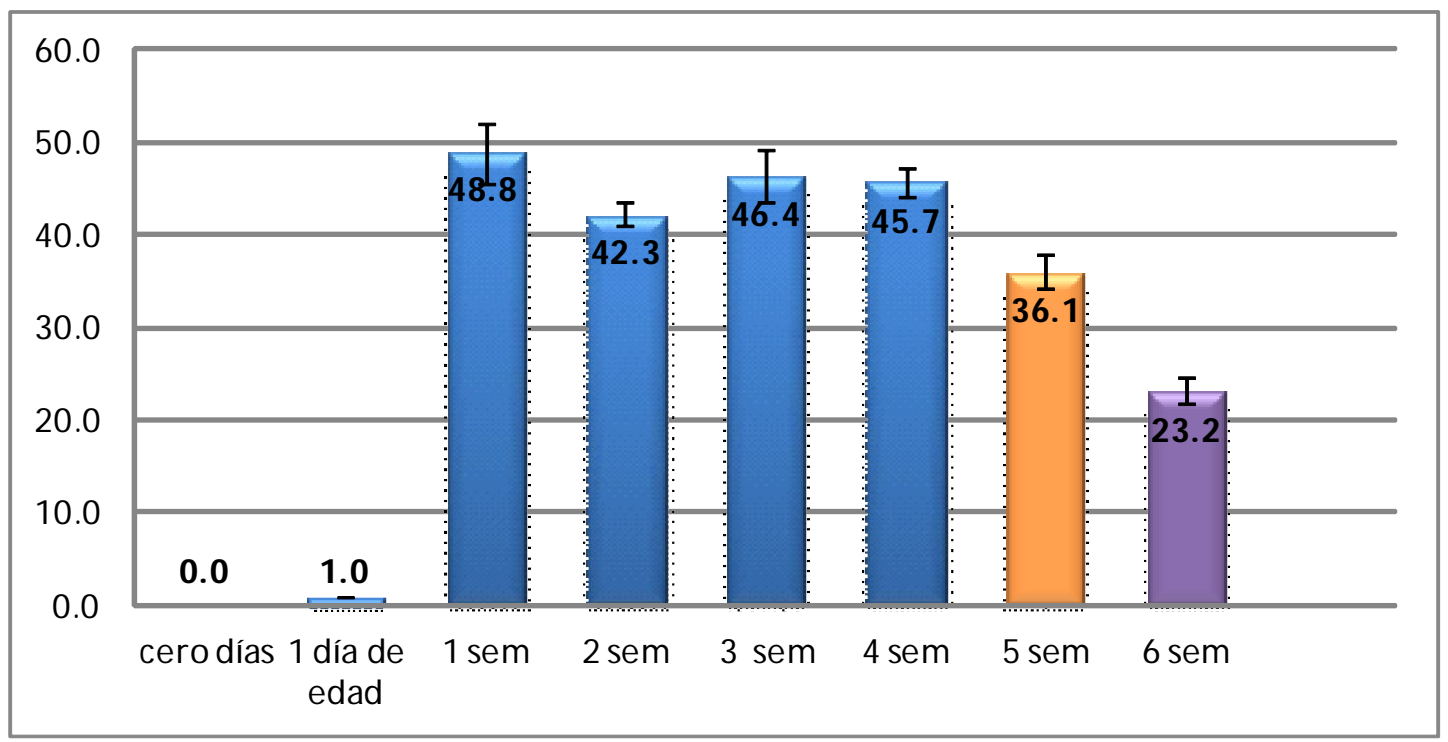

Figura 4. Variación de la expresión relativa de ARNm de IgA en mucosa intestinal de crías de alpacas, según el análisis $2^{-\triangle \Delta \mathrm{Ct}}$ para la expresión de ARNm de IgA en animales sanos según edad 


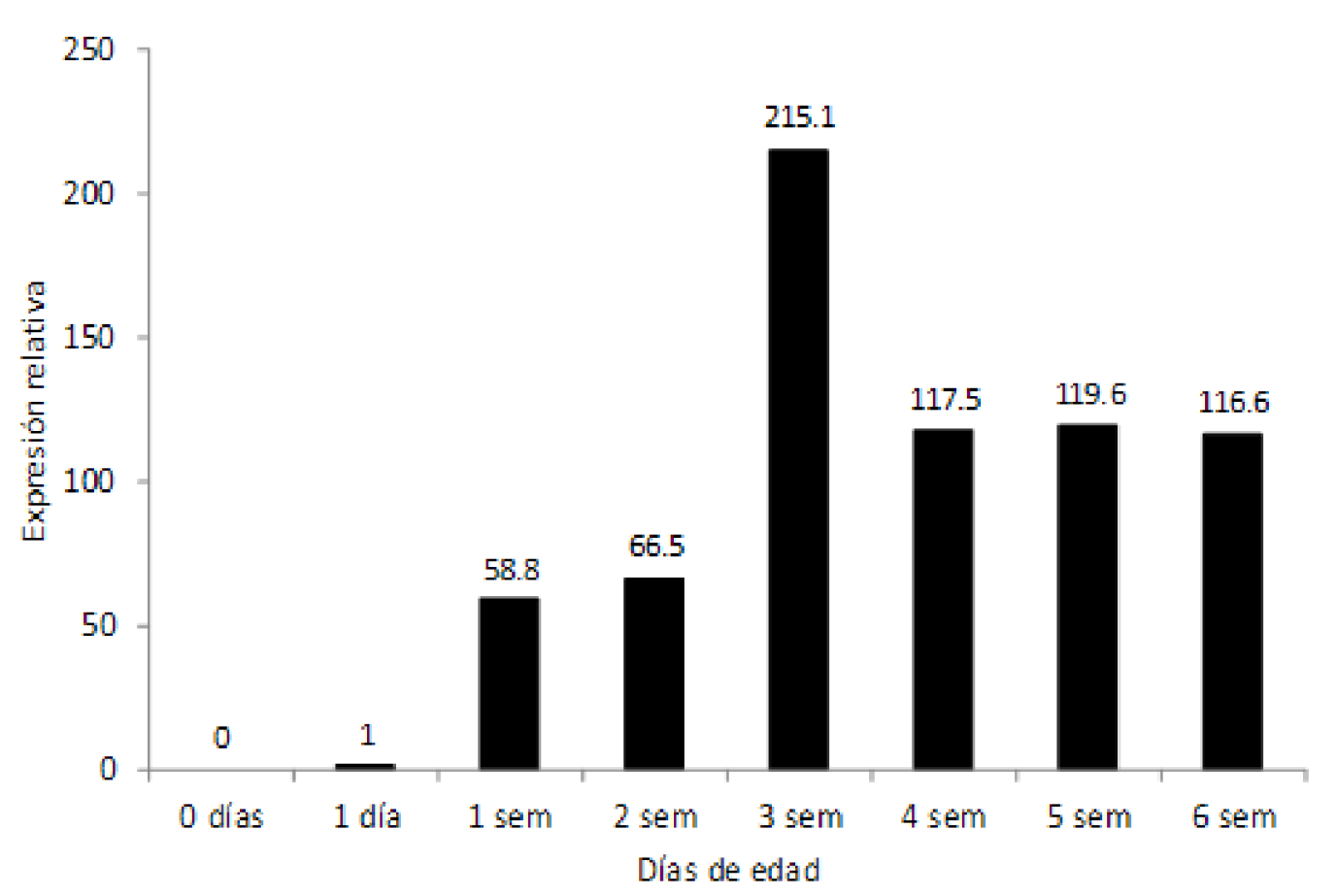

Figura 5. Variación de la expresión relativa de ARNm de IgA en mucosa intestinal de crías de alpacas, según el análisis $2^{-\Delta \Delta \mathrm{Ct}}$ para la expresión de ARNm de IgA en animales enfermos según edad

En los animales sanos se evidenció que no hubo expresión de IgA al nacimiento (0 días). Los niveles de expresión promedio de ARNm de IgA con respecto al calibrador en crías de alpaca sanas exhibieron una tendencia creciente en las primeras cuatro semanas de vida, decayendo a partir de la quinta semana de edad $(\mathrm{p}<0.05)$ (Fig. 4).

Los animales enfermos denotan expresión relativa de ARNm de IgA muy por encima de lo cuantificado para los animales de un día de edad (calibrador), llegando a producir durante la tercera semana de edad hasta 215 veces lo que estos producen. Los niveles de expresión descienden a partir de la cuarta semana $(p<0.05)$ y se mantienen constantes hasta la sexta semana (Fig. 5). Asimismo, también se encuentra diferencia significativa $(\mathrm{p}<0.05)$ al comparar los resultados de los animales sanos contra los valores de animales enfermos por grupos etarios con relación a los animales calibradores de un día de edad.

\section{Discusión}

El análisis de la Tm de los productos de RT-PCR tiempo real obtenidos de animales sanos y enfermos identificó temperaturas de disociación cercanas entre los amplicones resultantes (Fig. 2), existiendo predominancia de determinadas temperaturas en animales $\operatorname{sanos}\left(\mathrm{Tm}=85.7^{\circ} \mathrm{C}\right)$ y enfermos $\left(\mathrm{Tm}=86^{\circ} \mathrm{C}\right)$ (Cuadro 2). Esto determina la posible existencia de variantes de transcritos con diferencias muy ligeras en la composición de bases perceptible a través del tiempo real, ya que sus Tm son muy similares. El presente trabajo no pudo establecer con certeza la existencia de polimorfismos o isoformas procedentes de mecanismos de recombinación génica propias de la generación de los ARNm de $\operatorname{IgA}$ en alpacas, y para ello sería necesario realizar el secuenciamiento nucleotídico de los productos del RT-PCR tiempo real para identificar tales variaciones y emplear técni- 
cas avanzadas para develar las implicancias de tales cambios y sus efectos sobre los individuos en caso se presenten (Gould-Rothberg, 2001).

Los resultados obtenidos con el RT-PCR en tiempo real, usando oligonucleótidos diseñados para el ARNm de la IgA, permitieron establecer que los animales neonatos aparentemente sanos que no habían tomado calostro carecen de cantidades detectables de ARNm de $\operatorname{IgA}$ en la mucosa intestinal. Niveles detectables fueron producidos a partir del primer día de edad tras el consumo de calostro, debido a que la producción de IgA es dependiente del estímulo antigénico que está comenzando a presentarse con la colonización de microorganismos a nivel intestinal y también a las moléculas inductoras/reguladores de la respuesta inmune presente en el calostro y leche (Porto et al., 2007).

En este estudio se observaron casos de alpacas sanas (25\%) y enfermas $(30 \%)$ con niveles de ARNm de IgA indetectables a través de la técnica de RT-PCR tiempo real empleando los oligonucleótidos descritos. Esto podría ser debido a 1) la incapacidad de la prueba molecular de detectar ARNm de IgA carentes de la expresión del exón 1, considerando que se ha demostrado la existencia de ratones carentes de exón 1 alfa inducidos por altas dosis de LPS microbiano (Coffman et al., 1989); 2) la ocurrencia de animales inmunodeficientes que no puedan expresar la IgA; enfermedad denominada «deficiencia selectiva de IgA», que se presentan en una proporción de 1:500 a 1:700 individuos en ratones y en humanos, y que está asociada a alergias e infecciones recurrentes (Strober y Sneller, 1991); y 3) muchos individuos sanos presentan niveles basales de ARNm de IgA en cantidades no detectables, dado que no han sido estimulados para incrementar la producción de este anticuerpo.

Los niveles de expresión promedio de ARNm de IgA con respecto al calibrador en crías de alpaca sanas exhiben una tendencia creciente en las primeras cuatro semanas de vida, decayendo de manera discreta a partir de la quinta semana (Fig. 4). Los altos niveles de ARNm de IgA podrían estar asociadas a la presencia de moléculas inmunomoduladoras en calostro y leche, a la estimulación de los antígenos de la microbiota que se está implantando a partir de la ingesta del alimento materno y posteriormente por la ingesta de pasto natural (Porto et al., 2007). La posterior disminución de ARNm de IgA podría estar relacionada a procesos de tolerancia (supresión) inmunológica y sensibilización de antígenos alimentarios mediante la inducción de un mecanismo de un estado no específico de no respuesta inmunológica (MacDonald, 2001). Un resultado similar se aprecia en la producción de $\alpha$-defensinas en la mucosa intestinal de las crías de alpacas, sugiriendo que los procesos adaptativos hacia antígenos alimentarios inocuos y microbiota intestinal saprófita se extiende desde la inmunidad innata hasta la inmunidad adaptativa de manera dinámica en tejido intestinal en periodos de tiempo similares (More et al., 2011).

Los resultados muestran que los animales enfermos denotan expresión relativa de ARNm de IgA muy por encima de lo cuantificado para los animales de un día de edad (calibrador), llegando a producir durante la tercera semana de edad hasta 215 veces lo que estos producen (Fig. 5). El incremento significativo de la producción de ARNm de IgA frente a cuadros entéricos indica la capacidad de los animales jóvenes para responder adecuadamente mediante esta inmunoglobulina (IgA) ante la aparición de microorganismos patógenos (Hosono et al., 2003). Asimismo, las diferencias encontradas entre animales sanos y enfermos revelan estimulación y activación de la respuesta humoral a nivel intestinal en crías de alpaca enfermas con enteropatía (Zaldívar, 2002), particularmente importante en la quinta y sexta semana de edad donde los niveles de expresión de ARNm de IgA tienden a disminuir paulativamente en animales aparentemente sanos. 


\section{Conclusiones}

- Se identificó y demostró mediante la técnica de RT-PCR tiempo real que las alpacas codifican y transcriben ARNm del exón 1 de la región $\mathrm{Fc}$ de IgA desde el primer día de edad.

- Los animales sanos presentan una tendencia de expresión constante de ARNm de IgA hasta la cuarta semana de edad, con disminución discreta en las semanas subsiguientes, mientras que en los cuadros entéricos la producción de ARNm de IgA siempre es superior a lo expresado por los animales sanos.

\section{Agradecimientos}

Los autores agradecen a los criadores alpaqueros de las comunidades de la provincia de Canchis, Cusco, por su colaboración para la adquisición de los animales utilizados. El trabajo fue financiado por el Fondo Nacional de Innovación en Ciencia y Tecnología (FINCYT - PIBAP 2008), Contrato N. ${ }^{\circ} 065$ 2008.

\section{Literatura Citada}

1. Braathen R, Hohman V, Brandtzaeg P, Johansen F. 2007. Secretory antibody formation; conserved binding interaction between $\mathrm{J}$ chain and polymeric Ig receptor from humans and amphibians. J Immunol 178: 1589-1597.

2. Bustinza V. 2001. La alpaca. Conocimiento del gran potencial andino. Puno: Universidad Nacional del Altiplano. $496 \mathrm{p}$.

3. Coffman R, Lebman D, Shrader $E$. 1989. Transforming growth factor $\beta$ specifically enhances IgA. Production by lipopoly sacchraride-stimulated murine B lymphocytes. J Exp Med 170: 10391044.

4. Fagarasan S, Kinoshita K, Muramatsu M, Ikuta K, Honjo T. 2001. In situ class switching and differentiation to Ig-A producing cells in the gut lamina propia. Nature 413: 639-643.

5. Fagarasan S, Honjo T. 2003. Intestinal IgA synthesis: regulation of front-line body defenses. Nat Rev Immunol 3 (Suppl 1): 63-72.

6. Gould-Rothberg B. 2001. Mapping a role for SNPs in drug development. Nat Biotechnol 19: 209-211.

7. Hosono A, Ozawa A, Kato R, Ohnishi Y, Nakanishi Y, Kimura T, Nakamura R. 2003. Dietary fructooligosaccharides induce immunoregulation of intestinal IgA secretion by murine Peyer's patch cells. Biosci Biotechnol Biochem 67: 758-764.

8. MacDonald T. 2001. The reaction of the immune system to pathogens but not food antigens and commensal bacteria. Semin Immunol 13: 159-161.

9. More J, Manchego A, Sandoval N, Ramírez M, Pezo D, Kim Lam Chiok, Rivera H. 2011. Detección genómica y expresión de péptidos antimicrobianos ( $\alpha$ - y $\beta$-defensinas) en mucosa intestinal de crías de alpacas (Vicugna pacos). Rev Inv Vet Peru 22: 324-335.

10. Patil A, Hughes A, Zhang G. 2004. Rapid evolution and diversification of mammalian $\alpha$-defensins as revealed by comparative analysis of rodent and primate genes. Physiol Genomics 20: 1-11.

11. Porto A, Oliveira L, Ferraz L, Thomaz S, Rosa J, Roque-Barreira M. 2007. Isolation of bovine immunoglobulins resistant to peptic digestion: new perspectives in the prevention of failure in passive immunization of neonatal calves. J Dairy Sci 90: 955-962.

12. Ramírez M. 2009. La inmunoglobulina A secretoria en la mucosa intestinal de camélidos sudamericanos. Sistema de Revisiones en Investigaciones Veterinarias de San Marcos. [Internet]. Disponible en: http://www.unmsm.edu.pe/veterinaria/files/Articulo_mercy_Final.pdf

13. Strober W, Sneller M. 1991. IgA deficiency. Ann Allergy 66: 363-375. 
14. Tizard I. 2002. Inmunología veterinaria. $6^{a}$ ed. Madrid: McGraw-Hill. 517 p.

15. Urquieta B, Schiappacasse M, Raggi L, Martínez R, Ferguson JG. 1992. Sedación, inmunobilización y anestesia com xilacina-ketamina en vicuña
(Vicugna vicugna). Avances Cs Vet 7(2). [Internet]. Disponible en: http:// www.revistas.uchile.cl/index.php/ACV/ article/viewArticle/10425/10481

16. Zaldívar M. 2002. El sistema inmunológico de las mucosas. $\mathrm{Rev} \mathrm{Cu}$ bana Med Gen Integr 5: 24-36. 